\title{
Predictive factors for tooth loss during supportive periodontal therapy in patients with severe periodontitis: a Japanese multicenter study
}

\author{
Takahisa Hirata', Shinya Fuchida ${ }^{2 *}$,Tatsuo Yamamoto ${ }^{2}$, Chieko Kudo ${ }^{3}$ and Masato Minabe
}

\begin{abstract}
Background: Supportive periodontal therapy (SPT) must take individual patient risk factors into account. We conducted a multicenter joint retrospective cohort study to investigate the value of modified periodontal risk assessment (MPRA) and therapy-resistant periodontitis (TRP) assessment as predictive factors for tooth loss due to periodontal disease in patients with severe periodontitis during SPT.

Methods: The subjects were 82 patients from 11 dental institutions who were diagnosed with severe periodontitis and continued SPT for at least 1 year (mean follow-up =4.9 years) between 1981 and 2008. The outcome was tooth loss due to periodontal disease during SPT. The Cox proportional hazards model was used to analyze sex, age, diabetes status, smoking history, number of periodontal pockets measuring $\geq 6 \mathrm{~mm}$, rate of bleeding on probing, bone loss/age ratio, number of teeth lost, MPRA, and TRP assessment as explanatory variables.

Results: Univariate analysis showed that loss of $\geq 8$ teeth by the start of SPT [hazard ratio (HR) 2.86], MPRA score indicating moderate risk (HR 8.73) or high risk (HR 11.04), and TRP assessment as poor responsiveness to treatment (HR 2.79) were significantly associated with tooth loss $(p<0.05)$. In a model in which the explanatory variables of an association that was statistically significant were added simultaneously, the HR for poor responsiveness to treatment and $\geq 8$ teeth lost was significant at 20.17 compared with patients whose TRP assessment indicated that they responded favorably to treatment and who had lost $<8$ teeth by the start of SPT.

Conclusion: MPRA and TRP assessment may be useful predictive factors for tooth loss due to periodontal disease during SPT in Japanese patients with severe periodontitis. Additionally, considering the number of teeth lost by the start of SPT in TRP assessment may improve its predictive accuracy.
\end{abstract}

Keywords: Supportive periodontal therapy, Periodontal disease, Tooth loss, Periodontal risk assessment, Therapyresistant periodontitis

\section{Background}

Prevention and control of periodontal disease are an important issue for improving dental and oral health. A large-scale Japanese survey in 2005 found that periodontal disease was the major cause of permanent tooth extraction and that it accounted for a particularly high rate of extractions among those aged 30-60 years [1].

\footnotetext{
* Correspondence: fuchida@kdu.ac.jp

2Division of Dental Sociology, Department of Oral Science, Graduate School of Dentistry, Kanagawa Dental University, Yokosuka, Japan

Full list of author information is available at the end of the article
}

The results of Survey of Dental Diseases of 2016 showed that although the number of people with $\geq 20$ teeth had increased in all age groups, the proportion of those with periodontal pockets measuring $\geq 4 \mathrm{~mm}$ was high in almost all age groups and was particularly high among older people [2].

Supportive periodontal therapy (SPT) is treatment intended to stabilize the long-term condition of periodontal tissue after basic periodontal treatment or periodontal surgical treatment [3], which has been demonstrated to be effective $[4,5]$. Risk factors for individual patients must be

(c) The Author(s). 2019 Open Access This article is distributed under the terms of the Creative Commons Attribution 4.0 International License (http://creativecommons.org/licenses/by/4.0/) which permits unrestricted use, distribution, and reproduction in any medium, provided you give appropriate credit to the original author(s) and the source, provide a link to the Creative Commons license, and indicate if changes were made. The Creative Commons Public Domain Dedication waiver (http://creativecommons.org/publicdomain/zero/1.0/) applies to the data made available in this article, unless otherwise stated. 
taken into consideration in order to carry out SPT effectively, and previous studies have addressed risk factors for the recurrence of periodontitis and for tooth loss. Risk factors at the tooth level include the presence of probing depth (PD) $\geq 6 \mathrm{~mm}$ [6] and the type of tooth [7], and those at the patient level include age [8], genetic polymorphism [8], smoking history $[8,9]$, and systemic conditions such as diabetes [7]. Assessing these risk factors in combination rather than separately improves the accuracy with which tooth loss due to the recurrence of periodontitis can be predicted [10-12]. Additionally, several different models have been proposed as risk assessment indices, including the Periodontal Risk Calculator [10] and periodontal risk assessment (PRA) [11, 12].

Among these models, PRA takes account not only of the condition of periodontal tissue in terms of factors such as deep PD and percentage of sites positive for bleeding on probing (BOP), but also of smoking history and systemic conditions, and is widely used as a comprehensive risk assessment index at the patient level [13]. Previous studies of the association between PRA and prognosis during SPT for patients with moderate or severe periodontitis have found that patients assessed as high-risk by PRA are significantly more likely to experience tooth loss than those assessed as low-risk $[8,14,15]$. Recent studies have also found that the accuracy of prediction can be improved by excluding genetic risk factors (interleukin-1 genotype positive) from PRA [16] and changing the bone loss calculation method for determining the bone loss/age ratio [17]. Additionally, there is a need both to verify the value of combination risk assessment indices and improve the accuracy of prognosis predictions by focusing on individual risk factors. However, most previous studies of the association between PRA and tooth loss in patients with periodontitis have been carried out in Europe [18]. Moreover, it is unclear whether these associations apply in Japanese due to racial differences and differences in prevalence [19]. Risk assessment must also be universally applicable in dental institutions providing care in a variety of different formats. However, to date, few multicenter studies have been carried out.

In Japan, the therapy-resistant periodontitis (TRP) assessment diagnostic tool has been shown to be useful as a predictive factor for tooth loss during SPT [20]. TRP assesses the improvement rate of deep periodontal pockets in basic periodontal treatment based on previous studies $[21,22]$. TRP is defined as $<70 \%$ of sites with $\mathrm{PD} \geq 6 \mathrm{~mm}$ at initial examination that improved by $\geq 2$ $\mathrm{mm}$ after basic periodontal treatment. TRP diagnosis was found to be a significant risk factor for tooth loss with an odds ratio of $2.81(p=0.006)$ [20]. However, the outcome of tooth loss includes teeth lost to extractions due to causes other than periodontal disease. Furthermore, as the effect of differences between patients in the duration of SPT was also not taken into account in that analysis, further studies are required.

In this study, we carried out a multicenter joint retrospective cohort study to investigate the value of modified periodontal risk assessment (MPRA) and TRP assessment as predictive factors for tooth loss due to periodontal disease during SPT in patients with severe periodontitis. For MPRA, we modified the cut-off value of counting sites of PD from $\geq 5 \mathrm{~mm}$ to $\geq 6 \mathrm{~mm}$ [17] because subjects were restricted to those having severe periodontitis. Additionally, we used a Cox proportional hazards model that took follow-up period into account. We also evaluated the applicability of individual risk factors with the aim of further improving the accuracy of prediction.

\section{Methods \\ Patients}

To minimize variation among institutions in treatment strategies and treatments during SPT, the participating institutions comprised a university hospital and 10 dental clinics between 1981 and 2008. In the institutions, specialist periodontists and dental hygienists board-certified by the Japanese Society of Periodontology were employed full-time. As the subjects of a previous study [20], out of 1,614 patients with periodontitis undergoing regular examinations in these 11 institutions who had moved on to SPT after re-evaluation following the completion of basic periodontitis treatment or periodontal surgical treatment, we initially selected 208 patients with severe periodontitis on the basis of the following criteria: age $\geq 20$ years at initial examination, $\geq 16$ remaining teeth, and $\geq 1$ periodontal pocket measuring $\geq 6 \mathrm{~mm}$. In this study, severe periodontitis was defined as $\geq 1$ periodontal pocket measuring $\geq 6 \mathrm{~mm}$. Of these patients, 108 patients were excluded because of missing patient information from initial examination and the start of SPT, and 18 patients were excluded because they underwent SPT for $<1$ year, leaving 82 patients ( 34 men and 48 women) as the subjects of our analysis (Fig. 1). For 79 of the 108 patients who were excluded, either there was no X-ray image at the start of SPT to use for calculating the bone loss/age ratio or the X-ray image was unclear.

The study protocol was approved by the Ethics Committee of Aichi Gakuin University School of Dentistry (no. 276) and the Research Ethics Committee of Kanagawa Dental University (no. 388).

\section{Risk assessment indices}

Data on patient characteristics at the time of initial examination and the start of SPT were collected from medical records. Data comprised sex, age, diabetes status (under treatment), smoking history, number of sites with $\mathrm{PD} \geq 6 \mathrm{~mm}$ (6 points measured per tooth), percentage of sites positive for BOP, bone loss/age ratio (percentage of 


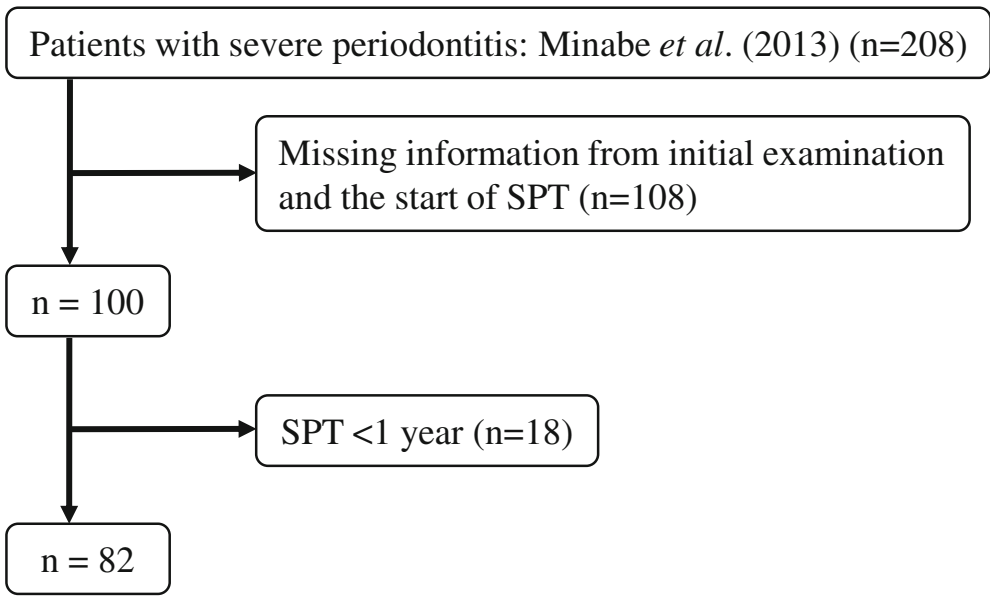

Fig. 1 Flow chart of the subjects for analysis

bone loss at the site of greatest tooth loss in the alveolar ridge on the surface adjacent to the molar region measured with the Schei ruler [23], divided by age), and the number of teeth lost out of a maximum of 28 (excluding the third molars).

MPRA was used as an overall risk assessment index and was scored out of a total of 6 risk factors. The patients were classed into three groups: patients with $\geq 5$ low-risk factors at the start of SPT were classed as low risk; patients with $\geq 2$ moderate risk factors (including patients with 1 moderate and 1 high-risk factor) were classed as moderate risk; and patients with $\geq 2$ high-risk factors were classed as high risk. However, because smoking history is evaluated solely on the basis of experience, it was used as a moderate risk factor.

We also used the TRP assessment [20], which calculates the proportion of sites of $P D \geq 6 \mathrm{~mm}$ at initial examination that improved by $\geq 2 \mathrm{~mm}$ after basic periodontal treatment. Patients in whom improvement was evident at $\geq 70 \%$ of sites were classed as favorable responsiveness to treatment, and those in whom it was evident in $<70 \%$ as poor responsiveness.

\section{Statistical analysis}

After descriptive analysis, an investigation was carried out using the Cox proportional hazards model with tooth loss due to periodontal disease during SPT as the outcome. Patient characteristics and risk evaluation indices at the time of initial examination and the start of SPT were included as explanatory variables. Specifically, for each explanatory variable, univariate analysis was performed and the hazard ratio (HR) and 95\% confidence interval $(95 \% \mathrm{CI})$ were calculated. For patients who underwent tooth extraction due to periodontal disease during SPT the follow-up period was considered
Table 1 Patient characteristics

\begin{tabular}{|c|c|c|c|}
\hline & & \multicolumn{2}{|l|}{ n (\%) } \\
\hline & & $\begin{array}{l}\text { Initial } \\
\text { examination }\end{array}$ & Start of SPT \\
\hline \multirow[t]{2}{*}{ Sex } & Male & $34(41.5)$ & \\
\hline & Female & $48(58.5)$ & \\
\hline \multirow[t]{5}{*}{ Age } & $\leq 34$ & $9(11.0)$ & $5(6.1)$ \\
\hline & $35-44$ & $25(30.5)$ & $20(24.4)$ \\
\hline & $45-54$ & $27(32.9)$ & $27(32.9)$ \\
\hline & $55-64$ & $16(19.5)$ & $24(29.3)$ \\
\hline & $\geq 65$ & $5(6.1)$ & $6(7.3)$ \\
\hline \multirow[t]{2}{*}{ Diabetes status } & Non-DM & 80 (97.6) & 80 (97.6) \\
\hline & DM & $2(2.4)$ & $2(2.4)$ \\
\hline \multirow[t]{2}{*}{ Smoking history } & Non-smoker & $62(75.6)$ & $62(75.6)$ \\
\hline & Smoker & $20(24.4)$ & $20(24.4)$ \\
\hline \multirow{2}{*}{$\begin{array}{l}\text { Number of sites with PD } \\
\geq 6 \mathrm{~mm}\end{array}$} & $<8$ & $6(7.3)$ & 80 (97.6) \\
\hline & $\geq 8$ & $76(92.7)$ & $2(2.4)$ \\
\hline \multirow[t]{2}{*}{ BOP } & $<25 \%$ & $13(15.9)$ & $69(84.1)$ \\
\hline & $\geq 25 \%$ & $69(84.1)$ & $13(15.9)$ \\
\hline \multirow[t]{2}{*}{ Bone loss/age ratio } & $<1.0$ & $16(19.5)$ & $25(30.5)$ \\
\hline & $\geq 1.0$ & $66(80.5)$ & $57(69.5)$ \\
\hline \multirow[t]{2}{*}{ Number of teeth lost } & $<8$ & $74(90.2)$ & $66(80.5)$ \\
\hline & $\geq 8$ & $8(9.8)$ & $16(19.5)$ \\
\hline \multirow[t]{3}{*}{ MPRA } & Low risk & & $27(32.9)$ \\
\hline & Moderate risk & & $34(41.5)$ \\
\hline & High risk & & $21(25.6)$ \\
\hline \multirow[t]{2}{*}{ TRP assessment } & Favorable & & $61(74.4)$ \\
\hline & Poor & & $21(25.6)$ \\
\hline
\end{tabular}

$D M$ diabetes mellitus, $P D$ probing depth, $B O P$ bleeding of probing, MPRA modified periodontal risk assessment, TRP therapy-resistant periodontitis 
Table 2 Association between the number of teeth lost due to periodontal disease during SPT and periodontal risk factors at the time of initial examination (Cox proportional hazards model)

\begin{tabular}{|c|c|c|c|c|c|c|c|}
\hline \multirow{2}{*}{$\begin{array}{l}\text { Initial examination } \\
\text { Variables }\end{array}$} & \multirow[t]{2}{*}{ Total } & \multicolumn{3}{|c|}{ Teeth loss due to periodontal disease during SPT } & \multirow[t]{2}{*}{$\mathrm{HR}$} & \multirow[t]{2}{*}{$95 \% \mathrm{Cl}$} & \multirow[t]{2}{*}{$p$ value } \\
\hline & & $\mathrm{n}$ & Person-years & Rate & & & \\
\hline \multicolumn{8}{|l|}{$\overline{S e x}$} \\
\hline Male & 34 & 7 & 159.3 & 0.0440 & 1.00 & & \\
\hline Female & 48 & 9 & 243.7 & 0.0369 & 0.77 & $0.29-2.08$ & 0.610 \\
\hline \multicolumn{8}{|l|}{ Age } \\
\hline$\leq 34$ & 9 & 3 & 31.8 & 0.0945 & 1.00 & & \\
\hline $35-44$ & 25 & 4 & 153.6 & 0.0260 & 0.28 & $0.61-1.26$ & 0.096 \\
\hline $45-54$ & 27 & 7 & 105.2 & 0.0666 & 0.76 & $0.19-2.97$ & 0.689 \\
\hline $55-64$ & 16 & 1 & 91.3 & 0.0110 & 0.11 & $0.01-1.10$ & 0.060 \\
\hline$\geq 65$ & 5 & 1 & 21.2 & 0.0472 & 0.51 & $0.05-5.00$ & 0.562 \\
\hline \multicolumn{8}{|l|}{ Diabetes } \\
\hline Non-DM & 80 & 16 & 398.1 & 0.0402 & 1.00 & & \\
\hline DM & 2 & 0 & 4.8 & 0.0000 & 0.05 & $0.00-6.27 \times 10^{7}$ & 0.777 \\
\hline \multicolumn{8}{|l|}{ Smoking history } \\
\hline Non-smoker & 62 & 11 & 301.2 & 0.0365 & 1.00 & & \\
\hline Smoker & 20 & 5 & 101.8 & 0.0491 & 1.41 & $0.49-4.09$ & 0.522 \\
\hline \multicolumn{8}{|c|}{ Number of sites with PD $\geq 6 \mathrm{~mm}$} \\
\hline$<8$ & 6 & 2 & 60.6 & 0.0330 & 1.00 & & \\
\hline$\geq 8$ & 76 & 14 & 342.3 & 0.0409 & 1.39 & $0.30-6.51$ & 0.680 \\
\hline \multicolumn{8}{|l|}{ BOP } \\
\hline$<25 \%$ & 13 & 5 & 87.5 & 0.0571 & 1.00 & & \\
\hline$\geq 25 \%$ & 69 & 11 & 315.4 & 0.0349 & 0.67 & $0.22-1.98$ & 0.465 \\
\hline \multicolumn{8}{|l|}{ Bone loss/age ratio } \\
\hline$<1.0$ & 16 & 1 & 67.8 & 0.0147 & 1.00 & & \\
\hline$\geq 1.0$ & 66 & 15 & 335.1 & 0.0448 & 3.19 & $0.42-24.17$ & 0.262 \\
\hline \multicolumn{8}{|c|}{ Number of teeth lost } \\
\hline$<8$ & 74 & 14 & 374.3 & 0.0374 & 1.00 & & \\
\hline$\geq 8$ & 8 & 2 & 28.6 & 0.0700 & 2.27 & $0.48-10.71$ & 0.300 \\
\hline
\end{tabular}

$H R$ hazard ratio, $C l$ confidence interval, $D M$ diabetes mellitus, $P D$ probing depth, $B O P$ bleeding of probing

to be from the date of the first appointment during SPT until the date of the extraction. Additionally, for those who did not undergo extraction it was considered to be from the date of the first appointment during SPT to the date of the last (most recent) appointment, with the former regarded as the occurrence of an event and the latter as terminated (follow-up completed).

Multivariate analysis simultaneously adding all explanatory variables for which a significant association was evident in univariate analysis was then performed, and its HR and 95\% CI were calculated.

IBM SPSS Statistics 23 (IBM Japan, Ltd., Tokyo, Japan) was used for statistical analysis, with $p<0.05$ regarded as significant.

\section{Results}

Table 1 shows the characteristics of the subjects included in our analysis at the time of initial examination and at the start of SPT. At the time of initial examination, the mean age was 47.2 years, the mean number of sites with $\mathrm{PD} \geq 6 \mathrm{~mm}$ was 39.9 , the mean percentage of sites positive for BOP was $50.6 \%$, the mean bone loss/ age ratio was 1.51 , and the mean number of teeth lost was $2.6 / 28$. The mean number of teeth extracted between basic periodontal treatment and the start of SPT was 1.4, and the mean number of teeth lost at the start of SPT was 4.0/28. The mean follow-up period after the start of SPT was 4.9 years, and the total follow-up period for all 82 patients was 402.9 person-years, with 16 patients (19.5\%) losing teeth. 
An investigation of the possible association between tooth loss due to periodontal disease during SPT and patient characteristics and risk assessment indices at the time of initial examination did not identify any significant associations (Table 2).

Table 3 shows the results of an investigation of the association between tooth loss due to periodontal disease during SPT and patient characteristics and risk assessment indices at the start of SPT. There were significant associations with the loss of $\geq 8$ teeth by the start of SPT (versus patients who had lost $<8$ teeth: HR 2.86, 95\% CI
1.02-8.01), MPRA score indicating moderate risk (versus low-risk patients: HR $8.73,95 \%$ CI 1.10-69.09) or high risk (versus low-risk patients: HR 11.04, 95\% CI 1.31-93.37), and TRP assessment as poor responsiveness to treatment (versus favorable responsiveness to treatment: HR 2.79, 95\% CI 1.05-7.44) $(p<0.05)$.

Table 4 shows models in which MPRA score, the number of teeth lost by the start of SPT (a component of MPRA), and TRP assessment, all of which exhibited a significant association in univariate analyses, were added simultaneously. In Model 1, in which MPRA score and

Table 3 Association between the number of teeth lost due to periodontal disease during SPT and periodontal risk factors at the start of SPT (Cox proportional hazards model)

\begin{tabular}{|c|c|c|c|c|c|c|c|}
\hline \multirow{2}{*}{$\begin{array}{l}\text { Start of SPT } \\
\text { Variables }\end{array}$} & \multirow[t]{2}{*}{ Total } & \multicolumn{3}{|c|}{ Teeth loss due to periodontal disease during SPT } & \multirow[t]{2}{*}{$\mathrm{HR}$} & \multirow[t]{2}{*}{$95 \% \mathrm{Cl}$} & \multirow[t]{2}{*}{$p$ value } \\
\hline & & $\mathrm{n}$ & Person-years & Rate & & & \\
\hline \multicolumn{8}{|l|}{ Age } \\
\hline$\leq 34$ & 5 & 1 & 14.2 & 0.0706 & 1.00 & & \\
\hline $35-44$ & 20 & 3 & 101.5 & 0.0296 & 0.36 & $0.04-3.57$ & 0.380 \\
\hline $45-54$ & 27 & 9 & 138.0 & 0.0652 & 0.76 & $0.09-6.33$ & 0.796 \\
\hline $55-64$ & 24 & 2 & 122.4 & 0.0163 & 0.20 & $0.02-2.30$ & 0.198 \\
\hline$\geq 65$ & 6 & 1 & 26.8 & 0.0373 & 0.46 & $0.03-7.51$ & 0.586 \\
\hline \multicolumn{8}{|l|}{ Diabetes } \\
\hline Non-DM & 80 & 16 & 398.1 & 0.0402 & 1.00 & & \\
\hline DM & 2 & 0 & 4.8 & 0.0000 & 0.05 & $0.00-6.27 \times 10^{7}$ & 0.777 \\
\hline \multicolumn{8}{|l|}{ Smoking history } \\
\hline Non-smoker & 62 & 11 & 301.2 & 0.0365 & 1.00 & & \\
\hline Smoker & 20 & 5 & 101.8 & 0.0491 & 1.41 & $0.49-4.09$ & 0.522 \\
\hline \multicolumn{8}{|c|}{ Number of sites with of PD $\geq 6 \mathrm{~mm}$} \\
\hline$<8$ & 80 & 16 & 396.7 & 0.0403 & 1.00 & & \\
\hline$\geq 8$ & 2 & 0 & 6.3 & 0.0000 & 0.05 & $0.00-3.81 \times 10^{6}$ & 0.743 \\
\hline \multicolumn{8}{|l|}{ BOP } \\
\hline$<25 \%$ & 69 & 13 & 356.9 & 0.0364 & 1.00 & & \\
\hline$\geq 25 \%$ & 13 & 3 & 46.0 & 0.0652 & 2.31 & $0.61-8.82$ & 0.219 \\
\hline \multicolumn{8}{|c|}{ Bone loss/age ratio } \\
\hline$<1.0$ & 25 & 4 & 116.9 & 0.0342 & 1.00 & & \\
\hline$\geq 1.0$ & 57 & 12 & 286.0 & 0.0420 & 1.21 & $0.39-3.76$ & 0.742 \\
\hline \multicolumn{8}{|c|}{ Number of teeth lost } \\
\hline$<8$ & 66 & 10 & 335.1 & 0.0298 & 1.00 & & \\
\hline$\geq 8$ & 16 & 6 & 67.8 & 0.0885 & 2.86 & $1.02-8.01$ & 0.046 \\
\hline \multicolumn{8}{|l|}{ MPRA } \\
\hline Low risk & 27 & 1 & 153.7 & 0.0065 & 1.00 & & \\
\hline Moderate risk & 34 & 9 & 161.1 & 0.0559 & 8.73 & 1.10-69.09 & 0.040 \\
\hline High risk & 21 & 6 & 88.2 & 0.0681 & 11.04 & $1.31-93.37$ & 0.027 \\
\hline \multicolumn{8}{|l|}{ TRP assessment } \\
\hline Favorable & 61 & 8 & 296.6 & 0.0270 & 1.00 & & \\
\hline Poor & 21 & 8 & 106.3 & 0.0752 & 2.79 & $1.05-7.44$ & 0.040 \\
\hline
\end{tabular}

HR hazard ratio, $C I$ confidence interval, $D M$ diabetes mellitus, $P D$ probing depth, BOP bleeding of probing, MPRA modified periodontal risk assessment, TRP therapy-resistant periodontitis 
Table 4 Associations between the number of teeth lost due to periodontal disease during SPT and risk assessment indices (Cox proportional hazards model)

\begin{tabular}{|c|c|c|c|c|c|c|}
\hline & \multicolumn{3}{|c|}{ Model 1} & \multicolumn{3}{|c|}{ Model 2} \\
\hline & $\mathrm{HR}$ & $95 \% \mathrm{Cl}$ & $p$ value & $\mathrm{HR}$ & $95 \% \mathrm{Cl}$ & $p$ value \\
\hline \multicolumn{7}{|l|}{ MPRA } \\
\hline Low risk & 1.00 & & & & & \\
\hline Moderate risk & 7.76 & $0.98-61.56$ & 0.053 & & & \\
\hline High risk & 11.17 & $1.31-94.90$ & 0.027 & & & \\
\hline \multicolumn{7}{|c|}{ Number of teeth lost } \\
\hline$<8$ & & & & 1.00 & & \\
\hline$\geq 8$ & & & & 4.06 & $1.41-11.65$ & 0.009 \\
\hline \multicolumn{7}{|l|}{ TRP assessment } \\
\hline Favorable & 1.00 & & & 1.00 & & \\
\hline Poor & 2.62 & $0.97-7.07$ & 0.057 & 4.41 & $1.44-13.49$ & 0.009 \\
\hline
\end{tabular}

$H R$ hazard ratio, $\mathrm{Cl}$ confidence interval, MPRA modified periodontal risk assessment, TRP therapy-resistant periodontitis

TRP assessment were added simultaneously, TRP assessment was no longer significant, but MPRA score indicating high risk had a significantly higher HR compared with a low-risk score (HR 11.17, 95\% CI 1.31-94.90). In Model 2, in which the number of teeth lost by the start of SPT and TRP assessment was added simultaneously, both variables were significant. A further investigation using a combination of two variables in Model 2 found that the $\mathrm{HR}$ for poor responsiveness to treatment and $\geq 8$ teeth lost was 20.17 (95\% CI 3.45-118.12) and was significantly high with respect to patients whose TRP assessment indicated that they were favorably responsive to treatment and who had lost $<8$ teeth by the start of SPT (Table 5).

\section{Discussion}

In this study, we investigated risk assessment indices that predicted tooth loss due to periodontal disease during SPT in patients diagnosed with severe periodontitis and undergoing treatment by specialist periodontists at 11 institutions in Japan. We found that PRA score, which is widely used in Europe, is valid in Japan. This is consistent with the results of studies in Germany $[8,16]$, France [24], Switzerland [14], Brazil [15], and the United
Kingdom [25], demonstrating the validity of PRA as a comprehensive risk assessment index. In terms of the individual component factors of PRA, in this study, the number of teeth lost was significantly associated with the number of teeth lost during SPT, a result consistent with those of previous studies [15, 24]. With respect to the other component factors of PRA score, with the exception of the number of sites with $P D \geq 6 \mathrm{~mm}$, some previous studies have found significant associations with other component factors, while others have found non-significant associations. No previous study, including this one, has identified a significant association with the presence of high frequencies of deep residual pockets $[8,14-16,24,25]$.

The TRP assessment, which is under consideration in Japan, switched the outcome from extractions for any reason to extractions due to periodontal disease in response to an issue raised in a previous study [20] and has also been found to be effective when the duration of SPT is taken into account. Our results suggested that its predictive accuracy could be further improved by taking account of the number of teeth lost by the start of SPT. Patients who have lost more teeth may be at higher risk of tissue breakdown due to periodontal disease, which may cause further tooth loss in the future. Previous studies have also shown that the greater the number of teeth lost, the higher the risk for further tooth loss during SPT or the maintenance phase $[15,26]$, and the use of a combination of PRA and TRP assessment may further improve predictive accuracy.

The patients who were the subjects of our analysis were similar to those of previous studies of the effectiveness of PRA in terms of age and severity of periodontitis $[8,14-16,24,25]$. However, the number of study subjects and the mean number of teeth lost during SPT and the overall follow-up period were both somewhat smaller. A comparison of previous studies that, like this study, also included patients with both aggressive and chronic periodontitis $[8,24]$ showed that the mean number of teeth lost was smaller in this study. This suggested that in this study SPT contributed to preventing tooth loss due to periodontal disease, further reinforcing the importance of SPT after periodontal treatment.

Table 5 Associations between the number of teeth lost due to periodontal disease during SPT and a combination of TRP assessment and the number of teeth lost by the start of SPT (Cox proportional hazards model)

\begin{tabular}{|c|c|c|c|c|c|c|c|c|}
\hline \multirow{2}{*}{$\begin{array}{l}\text { TRP } \\
\text { assessment }\end{array}$} & \multirow{2}{*}{$\begin{array}{l}\text { Number of } \\
\text { teeth lost }\end{array}$} & \multirow[t]{2}{*}{ Total } & \multicolumn{3}{|c|}{ Teeth loss due to periodontal disease during SPT } & \multirow[t]{2}{*}{$H R$} & \multirow[t]{2}{*}{$95 \% \mathrm{Cl}$} & \multirow[t]{2}{*}{$p$ value } \\
\hline & & & $\mathrm{n}$ & Person-years & Rate & & & \\
\hline Favorable & $<8$ & 47 & 4 & 234.9 & 0.0170 & 1.00 & & \\
\hline Favorable & $\geq 8$ & 14 & 4 & 61.7 & 0.0649 & 3.70 & $0.91-14.98$ & 0.067 \\
\hline Poor & $<8$ & 19 & 6 & 100.2 & 0.0599 & 3.48 & $0.98-12.35$ & 0.053 \\
\hline Poor & $\geq 8$ & 2 & 2 & 6.2 & 0.3243 & 20.17 & $3.45-118.12$ & 0.001 \\
\hline
\end{tabular}

HR hazard ratio, $\mathrm{Cl}$ confidence interval, TRP therapy-resistant periodontitis 
With respect to the study design, most previous studies have used a logistic regression model. However, although some studies used a uniform duration of SPT [15] or a model that took the duration of SPT into account [14], a couple failed to consider differences in the duration of SPT $[8,24]$. Although some studies took tooth loss due to periodontal disease as the outcome $[14,24]$, most used tooth loss for any reason $[8,15,16,25]$. On this point, in our study, we used a Cox proportional hazards model that took differences in the duration of SPT into account and restricted tooth loss to that due to periodontal disease, enabling the risk of periodontal disease to be more accurately predicted.

Finally, this study has some advantages. This was a multicenter joint study performed in both a university hospital and dental clinics, and the consistency of periodontal treatment was assured because diagnosis and treatment were performed by specialist periodontists. This study also used a Cox proportional hazards model limited to extractions due to periodontal disease. However, it had the limitations that many subjects were excluded because of difficulties in calculating the bone loss/age ratio, it included only two patients with diabetes, smoking history was evaluated solely on the basis of experience rather than quantitatively, and the bone loss/age ratio was overestimated in younger patients with major bone loss [17]. Furthermore, we did not evaluate bifurcation lesions, which have been shown to be associated with tooth loss in previous studies [27-29]. Moreover, modification of cut-off values of PD from $\geq 5$ $\mathrm{mm}$ to $\geq 6 \mathrm{~mm}$ might result in underestimation of the predictability of the PRA model. Because only patients with severe periodontitis were included and residual sites with $\mathrm{PD} \geq 6 \mathrm{~mm}$ are known as incompletely treated sites [6], we modified the model. Further studies of more patients will be required to confirm our results.

\section{Conclusion}

PRA and TRP assessment may be useful predictive factors for tooth loss due to periodontal disease during SPT in Japanese patients with severe periodontitis. Additionally, considering the number of teeth lost by the start of SPT in TRP assessment may improve its predictive accuracy.

\section{Abbreviations}

BOP: Bleeding on probing; Cl: Confidence interval; HR: Hazard ratio; MPRA: Modified periodontal risk assessment; PD: Probing depth; PRA: Periodontal risk assessment; SPT: Supportive periodontal therapy; TRP: Therapy-resistant periodontitis

\section{Acknowledgments}

The authors would like to express our gratitude to Satomi Takano, Kazuo Harai, Koji Inagaki, Yuko Nagaki, Joji Urushihara, Toshiro Kodama, Makiko Katsuki, Takashi Sugiyama, Tokuko Sato, Kanji Kouno, Rie Nakanishi, Katsuaki Higashi, Mina Honda, Masae Nakazawa, Hiroaki Seino, Takeo Taniguchi, Junko Horiuchi, Yuko Yamamoto, Itaru Kaneko, Miho Ito, Akira Makino, Sumie Kurokawa, Mari Kato, and Toshihide Noguchi.

\section{Funding}

This study was supported by Grant-in-planning for Advanced Research (2012) from the Japanese Society of Periodontology.

\section{Availability of data and materials}

The datasets generated and/or analyzed during the current study are not publicly available as the ethics approval was granted on the basis that only researchers involved in the study could access the de-identified data. Raw data have been stored securely at Kanagawa Dental University.

\section{Authors' contributions}

$\mathrm{TH}$ conducted the study as part of his PhD thesis with the Graduate School of Dentistry, Kanagawa Dental University. SF, TY, and CK provided assistance with study design, data analysis and critical revision of the manuscript. MM is the principal investigator of a multicenter joint study, helped to develop the idea of the study, participated in acquiring the data and the study design. All authors read and approved the final manuscript.

\section{Ethics approval and consent to participate}

This study was approved by the Ethics Committee of Aichi Gakuin University School of Dentistry (no. 276) and the Research Ethics Committee of Kanagawa Dental University (no. 388) and conformed to the principles of the Declaration of Helsinki. All participants gave written informed consent to participate, and their anonymity was preserved.

\section{Consent for publication}

Not applicable.

\section{Competing interests}

The authors declare that they have no competing interests.

\section{Publisher's Note}

Springer Nature remains neutral with regard to jurisdictional claims in published maps and institutional affiliations.

\section{Author details}

${ }^{1}$ Division of Periodontology, Department of Oral Interdisciplinary Medicine, Graduate School of Dentistry, Kanagawa Dental University, Yokosuka, Japan. ${ }^{2}$ Division of Dental Sociology, Department of Oral Science, Graduate School of Dentistry, Kanagawa Dental University, Yokosuka, Japan. ${ }^{3}$ Institute of Medical Corporation Shinsekai, Tokyo, Japan.

Received: 30 October 2018 Accepted: 4 January 2019

Published online: 15 January 2019

\section{References}

1. Ando Y, Aida J, Morita M, Aoyama S, Masui M. Report of reason for permanent tooth extraction. 8020 Promotion Foundation; 2005 (In Japanese).

2. Ministry of Health, Labour and Welfare. Results of Survey of Dental Diseases of 2016. https://www.mhlw.go.jp/toukei/list/62-28.html. Accessed 10 Aug 2018.

3. Japanese Society of Periodontology. JSP clinical practice guideline for the periodontal treatment, 2015 (English version): Ishiyaku Publishers; 2017.

4. Axelsson $\mathrm{P}$, Lindhe J. The significance of maintenance care in the treatment of periodontal disease. J Clin Periodontol. 1981;8:281-94.

5. Renvert S, Persson GR. Supportive periodontal therapy. Periodontol 2000. 2004;36:179-95.

6. Matuliene G, Pjetursson BE, Salvi GE, Schmidlin K, Brägger U, Zwahlen M, Lang NP. Influence of residual pockets on progression of periodontitis and tooth loss: results after 11 years of maintenance. J Clin Periodontol. 2008;35: 685-95.

7. Faggion CM Jr, Petersilka G, Lange DE, Gerss J, Flemmig TF. Prognostic model for tooth survival in patients treated for periodontitis. J Clin Periodontol. 2007:34:226-31.

8. Eickholz P, Kaltschmitt J, Berbig J, Reitmeir P, Pretzl B. Tooth loss after active periodontal therapy. 1: patient-related factors for risk, prognosis, and quality of outcome. J Clin Periodontol. 2008;35:165-74.

9. Chambrone L, Chambrone D, Lima LA, Chambrone LA. Predictors of tooth loss during long-term periodontal maintenance: a systematic review of observational studies. J Clin Periodontol. 2010;37:675-84. 
10. Page RC, Martin J, Krall EA, Mancl L, Garcia R. Longitudinal validation of a risk calculator for periodontal disease. J Clin Periodontol. 2003;30:819-27.

11. Lang NP, Tonetti MS. Periodontal risk assessment (PRA) for patients in supportive periodontal therapy (SPT). Oral Health Prev Dent. 2003;1:7-16.

12. Kye W, Davidson R, Martin J, Engebretson S. Current status of periodontal risk assessment. J Evid Based Dent Pract. 2012;12:2-11.

13. Lang NP, Suvan JE, Tonetti MS. Risk factor assessment tools for the prevention of periodontitis progression a systematic review. I Clin Periodontol. 2015:42:S59-70.

14. Matuliene G, Studer R, Lang NP, Schmidlin K, Pjetursson BE, Salvi GE, Brägger U, Zwahlen M. Significance of periodontal risk assessment on the recurrence of periodontitis and tooth loss. J Clin Periodontol. 2010;37:191-9.

15. Costa FO, Cota LO, Lages EJ, Lima Oliveira AP, Cortelli SC, Cortelli JR, Lorentz TC, Costa JE. Periodontal risk assessment model in a sample of regular and irregular compliers under maintenance therapy: a 3-year prospective study. J Periodontol. 2010;83:292-300.

16. Meyer-Bäumer A, Pritsch M, Cosgarea R, Sayed NE, Kim TS, Eickholz P, Pretzl B. Prognostic value of the periodontal risk assessment in patients with aggressive periodontitis. J Clin Periodontol. 2012;39:651-8.

17. Lü D, Meng H, Xu L, Lu R, Zhang L, Chen Z, Feng X, Shi D, Tian Y, Wang X. New attempts to modify periodontal risk assessment for generalized aggressive periodontitis: a retrospective study. J Periodontol. 2013;84:1536-45.

18. Nibali L, Farias BC, Vajgel A, Tu YK, Donos N. Tooth loss in aggressive periodontitis: a systematic review. J Dent Res. 2013;92:868-75.

19. Kassebaum NJ, Bernabé E, Dahiya M, Bhandari B, Murray CJ, Marcenes W. Global burden of severe tooth loss: a systematic review and meta-analysis. J Dent Res. 2014;93:20S-8S.

20. Minabe M, Takano S, Harai K, Inagaki K, Nagaki Y, Urushihara J, Kodama T, Katsuki M, Sugiyama T, Sato T, et al. Patient-related prognostic risk factors in severe periodontitis patients after periodontal therapy. I Jpn Soc Periodontol. 2013;55:170-82 (In Japanese).

21. Axtelius B, Söderfeldt B, Edwardsson S, Attström R. Therapy-resistant periodontitis (II). Compliance and general and dental health experiences. J Clin Periodontal. 1997;24:646-53.

22. Hughes FJ, Syed M, Koshy B, Bostanci N, McKay IJ, Curtis MA, Marcenes W, Croucher RE. Prognostic factors in the treatment of generalized aggressive periodontitis: Il. Effects of smoking on initial outcome. J Clin periodontal. 2006;33:671-6

23. Schei O, Waerhaug J, Lovdal A, Arno A. Alveolar bone loss as related to oral hygiene and age. J Periodontol. 1959;30:7-16.

24. Leininger M, Tenenbaum H, Davideau JL. Modified periodontal risk assessment score: long-term predictive value of treatment outcomes. A retrospective study. J Clin Periodontol. 2010;37:427-35.

25. Nibali L, Sun C, Akcalı A, Meng X, Tu YK, Donos N. A retrospective study on periodontal disease progression in private practice. J Clin Periodontol. 2017; 44:290-7.

26. Yamamoto T, Tsuneishi M, Murakami C, Watanabe T. Retrospective study on tooth loss during maintenance care in a university hospital. J Dent Hlth. 2007;57:632-9 (In Japanese).

27. Dannewitz B, Krieger JK, Hüsing J, Eickholz P. Loss of molars in periodontally treated patients: a retrospective analysis five years or more after active periodontal treatment. J Clin Periodontol. 2006;33:53-61.

28. Saminsky M, Halperin-Sternfeld M, Machtei EE, Horwitz J. Variables affecting tooth survival and changes in probing depth: a long-term follow-up of periodontitis patients. J Clin Periodontol. 2015;42:513-9.

29. Dannewitz B, Zeidler A, Hüsing J, Saure D, Pfefferle T, Eickholz P, Pretzl B. Loss of molars in periodontally treated patients: results 10 years and more after active periodontal therapy. J Clin Periodontol. 2016;43:53-62.

Ready to submit your research? Choose BMC and benefit from:

- fast, convenient online submission

- thorough peer review by experienced researchers in your field

- rapid publication on acceptance

- support for research data, including large and complex data types

- gold Open Access which fosters wider collaboration and increased citations

- maximum visibility for your research: over $100 \mathrm{M}$ website views per year

At $\mathrm{BMC}$, research is always in progress.

Learn more biomedcentral.com/submissions 